\title{
Research on Teaching Method System of Insurance in Independent College
}

\author{
Ying Hu ${ }^{1}$, Zhenxing $\mathrm{Ge}^{2}$ \\ ${ }^{1}$ College of Technology and Art Jingdezhen Ceramic Institute, Jingdezhen, Jiangxi Province, China \\ ${ }^{2}$ College of Technology and Art Jingdezhen Ceramic Institute, Jingdezhen, Jiangxi Province, China
}

Keywords: independent college; insurance science; teaching method system

\begin{abstract}
As a compulsory core course of Finance Department of the Ministry of education, insurance science involves various disciplines such as finance, law, medicine, mathematics, economics and so on. The course is very theoretical and practical, but the effect of teaching shows that the application ability of students' theoretical knowledge is still insufficient, and the teaching method of "insurance" needs to be reformed. In view of the teaching practice in independent college, it is necessary to look at various teaching methods in a dialectical view, regard each method as an inseparable part of the organic whole. To build insurance teaching method system, a variety of teaching methods can be introduced and applied, such as case teaching, discussion teaching, heuristic teaching, multimedia teaching, task driven teaching, etc., which gives full play to the leading role and interaction between teachers and students, improves teaching effect, and meets the training goal of applied talents in independent colleges.
\end{abstract}

\section{Introduction}

It is the inherent demand of independent colleges to cultivate high-quality applied talents in order to adapt to market demand. To explore various teaching modes or methods which are helpful for the training of Applied Talents in the course of education and teaching in independent colleges, will teach students to apply various professional theoretical knowledge to practice flexibly, and it's the necessary work for the course construction of independent colleges.

As a cross - permeable course in the field of mathematics, technology and sociology, insurance science is not only theoretical, but also practical and applied. However, long term teaching experience shows that, depending on the traditional teaching methods, the teaching effect of the course will be discounted, the students' learning enthusiasm is not so good, the theory and practice of insurance can not be well combined. It is of great significance to reform and study the teaching method system of "insurance" in the independent college.

\section{The Main Problems in the Teaching of Insurance Course in Independent Colleges}

\subsection{Disconnection between theory and practice}

From the characteristics of insurance, insurance science should be a more pragmatic course, so its teaching should be closely linked with various insurance practices. However, it is not the case. Although we have also excavated and adopted a large number of cases in the past teaching, in some aspects, the content is still empty and divorced from practice. Most of the domestic textbooks are still theoretical and identical. On the other hand, students need to know most about the insurance that is closely related to the life of the people, such as pension, medical care, education, engineering insurance and so on. Many independent colleges have not set up corresponding practice courses. The lack of practical teaching leads to the disconnection between theory and practice, which greatly reduces the teaching effect.

\subsection{The obsolete way of teaching}

Because of the traditional teaching mode, our insurance course can not arouse the students' enthusiasm for learning, and it also greatly affects the students' participation, which results in the 
unsatisfactory of students' learning effect. Although some teachers have introduced some multimedia teaching equipment and case, there is still no fundamental change in the core. The traditional teaching concept is still deep-rooted, the whole teaching mode is still set up to deal with the examination, so that the students do not learn the key knowledge in insurance.

\subsection{Weak teacher resources}

The content of insurance business is mixed, the echelon is much. To master the business skillfully, the students must do a lot of practical operation and get the careful guidance of the senior insurance agent. Therefore, insurance professional education must have enough powerful faculty to accomplish such arduous teaching tasks. In fact, most of our independent college insurance professional teachers are seriously inadequate. Lack of "double teacher" teachers, lack of insurance practice knowledge, will result in the lack of practical and timeliness of the course teaching, thus affect the teaching effect.

\subsection{Students' lack of motivation in learning}

Due to the late start and low level of the insurance industry in China, some insurance practitioners are irregularities for high commission, resulting in many consumers' distrust of the insurance industry. It is believed that the insurance products are deceptive, the employees' quality is not high and the reputation of insurance companies is affected. These understandings also exert a subtle influence on students.

\section{The Establishment of Insurance Teaching Methodology System in Independent Colleges}

\subsection{Embody the characteristics of independent colleges}

In terms of talent cultivation, independent colleges are more inclined to cultivate applied high-level professionals. Therefore, the course of the "insurance" course of the independent college has its own uniqueness: on the one hand, it strengthens the theory teaching, the students grasp the basic theory of the comprehensive "insurance", meet the needs of its practical innovation, on the other hand, we should pay attention to the training of students' ability to connect the theory with the practice, and let the students understand the practical operation knowledge of insurance contract and the operation of insurance market through the training course, thus their work ability is improved. In the course of teaching and research, teachers must always adhere to the theory and practice. While teaching the basic theory systematically, we need to pay attention to the training of students' practical ability.

\subsection{The starting point is "student centered" and "market-oriented"}

Professional teachers should quickly adjust their mindset, walk down A standing rostrum, and establish the principle of "student centered". Teachers are no longer the machine of knowledge export, but also the guide of students. Students are no longer passive listeners, but the active, self-learning learners, researchers, practitioners and participants. At the same time, many students, like most civilians, have a deep mind and even prejudice to the insurance industry, because they lack clear and rational understanding of industry status, career positions and capabilities. If we can strengthen the direct communication between the students and the market and create conditions for them to practice more, the students will gradually change their ideas and form an objective and dialectical evaluation of the insurance industry.

\subsection{Build an organic system with diversified teaching methods}

(1) The use of case teaching method. The case teaching method is a new teaching method, which is enlightening and practical, and can help students to set up the idea of management contingency theory, enrich the background knowledge, and improve the students' decision-making ability and comprehensive quality. For some theoretical and abstract insurance knowledge, by increasing interesting cases, learning atmosphere can be adjusted, and students' interest in learning will become stronger. For example, the management and management of the insurance industry is a 
more boring practical problem. The students' interest in learning is not high. If the related cases are added in the teaching, such as the insurance disputes caused by the insurance agent, the subrogation in the process of claim compensation and so on, it can be clearly felt that the attention of the students is concentrated and the atmosphere in the classroom is alive.

The case can guide students to think about the relevant principles, and truly combine theory and practice, so that students can better master the professional knowledge of insurance and learn to use it. For example, when it comes to the principle of proximate cause, the decision of the proximate cause is very professional. It involves many fields such as medicine, law, logic and so on. It is difficult for students to make mistakes in their essence. The task group has consciously added a lot of cases in the teaching. The case has a clear and complicated case, and it emphasizes the immediate causes and causes. The difference, a semester down, the students can have a more proficient analysis of the origin of insurance disputes, to find out the decisive factors of the case, the effect is very obvious.

In case teaching, the way of student analysis and teacher comment also increases interaction and communication between teachers and students, and harmonize the relationship between teachers and students. On the one hand, it encourages the students to make continuous progress and constantly break through; on the other hand, the teachers have also raised higher requirements for teachers to constantly update their knowledge structure, constantly strengthen their own theoretical accomplishment, and form a good atmosphere of "teaching and learning".

(2) The use of task driven teaching method. The form of task driven teaching method includes task proposing -- task analysis -- task solving -- summary and evaluation. According to the different course contents, some tasks can be put forward in the class. Once the students have reached the task, this lesson should be completed, after the students' discussion and the teacher's enlightenment and guidance. They should clear the hidden knowledge, distinguish the old and new knowledge, and find ways to solve the problem. All of these can make them to have a strong interest in learning and they are willing to be organized to communicate and discuss, work together to solve problems. Task driven method enables students to have more time and opportunities to discuss, communicate or discuss with each other, analyze and solve problems, so that students' thinking process can be displayed.

(3) Appropriate choice of situational teaching method. Situational teaching method refers to a way of teaching students' cognitive activities and emotional activities by making full use of images and creating typical scenes. When we have a class, a few key questions should be put forward first, then the teacher narrates the situation or plays the multimedia. The students will naturally focus on finding the problems in the situation and master the connections and answers of all the problems. In this way, the students can not only understand the important content of their study, stimulate the students' curiosity, but also cultivate their learning ability.

Or we can arrange the students to play the possible positions in the future, make a set of test projects similar to the actual requirements of the job, and arrange the subjects in a simulated and realistic working environment. So the students will feel the working atmosphere, and enhance their ability to deal with the actual problems.

(4) Full integration of heuristic and discussion teaching method. According to the teaching content, the teacher puts forward the questions which are closely related to the real life, then the students express their opinions on these questions, so that they can achieve the purpose of mastering knowledge and exchanging ideas. It's just the classroom discussion method. For example, when teaching insurance funds, we can let students discuss the problem of "whether the basic endowment insurance fund of our country can enter the security market". Students can analyze based on the economic environment, the stock market and so on. It not only stimulates the students' learning enthusiasm, but also improves the students' ability to analyze and solve problems.

(5) Comprehensive exercises can not be omitted. In the course of teaching, teachers have a plan to assign some exercises to students, which is helpful to improve the students' ability to understand, analyze and solve problems. It is an effective way of teaching. In the setting of the exercises, teachers can raise questions from a variety of angles and types which combine the classroom 
teaching and the thinking problems in the textbook, and ask the students to answer in writing. For example, when it comes to personal insurance, the corresponding questions can be drawn up, such as "the difference between social pension insurance and commercial life insurance", which requires the students to find out the information widely and distinguish them from different angles. This is not only good for deeping the students' understanding of the principles or complementarity of social insurance and commercial insurance. It also helps to guide students to learn independently and cultivate their thinking of combining theory with practice.

(6) Create conditions to implement the social practice teaching method. In order to improve the effectiveness of the teaching, we must give the students more opportunities of social practice. We can lead the students to visit insurance companies, such as Pingan Group and China Life, carry out the investigation and promotion of insurance in the society, and improve the operation skills through social practice.

\section{Pay Attention to the Application of the Insurance Teaching Methodology System}

\subsection{Case teaching method has many aspects to be noticed in its application}

Firstly, choose the case properly. The insurance cases should be typical, realistic and enlightening. It is necessary to select the typical cases which are closely related to the teaching content and purpose, to strengthen the effect of case teaching; select the cases closely related to our life, to strengthen the students' feeling of kindness, to make the students more easy to understand the case, to pay attention to the timeliness of the cases, and to keep pace with the times.

Secondly, we should strengthen the discussion process of case teaching. There are four steps to, such as showing case - case discussion - case conmunicating and a summar. A panel is set up to discuss the task, and the members of the group are asked to conduct a group discussion and communicate in the class discussion on the basis of consulting the relevant information. Finally, the teacher reviews the comments.

Thirdly, case teaching should be combined with multimedia technology, which is both advanced and efficient. Students will receive the most information in the shortest time, their learning enthusiasm efficiency is improved.

\subsection{There are many notices in the application of task-based teaching}

First of all, we should carefully design tasks combined with the characteristics of students. The task must be original and attractive, can properly explain the problems, or include the new knowledge. Secondly, we are going to give students the room for thinking and trying. They should be inspired by trying and exploring to find problems, to encourage them to be good at Infer other things from one fact. Thirdly, we should pay attention to the difference of individual inquiry ability. Combine individual self study, group discussion, cooperative inquiry and teacher's explanation, so that everyone can participate, state his opinions. Finally, it needs to be used in conjunction with other methods, such as teaching, discussing, answering questions, cases, hiring judges or lawyers, using multimedia teaching and so on. Teachers should alternate or use them in accordance with the actual situation.

\subsection{The use of various teaching methods should grasp the time and control process well}

The comprehensive adoption of those teaching methods will enable students to expand and extend the interest issues involved in the process of collecting and sorting out related materials and discussions. These extended problems must be discussed in class. It occupies certain classes. However, as the overall course is certain, these additional contents have formed the conflict of the total time of teaching, and the teacher needs the flexible control.

At the same time, the teaching process should be controlled. The case should be provided to students in advance, so that students can have enough time to read and be familiar with cases, to fully consider and discuss. When we have a class discussion, students speak freely, and analyze the key points of cases, under the guidance of the teacher which can prevent deviation from the subject. 


\subsection{The application of the insurance teaching method system of has higher requirements for teachers}

First of all, teachers should not only have solid theoretical knowledge, but also have practical operation ability. Teachers need to restructure the whole knowledge system, and use different teaching methods to display different modules. Teachers should be arranged to the insurance company to practice and improve the application ability. So the learning conditions for students will be better.

\section{Conclusion}

Secondly, teachers should be able to express clearly, listen carefully and think quickly so that they can correctly guide the students to carry out a targeted discussion. They should study new theories, grasp modern educational technology in time. Otherwise, the discussion may become a general discussion, or become an endless argument.

\section{References}

[1] Zhang Hongtao, Insurance (Fourth Edition), China Renmin University Press, 2014

[2] Liu Yonggang, Case Study of Insurance, China Financial and Economics Publishing House, 2016

[3] Law Publishing Center, Annotation of People's Republic of China Insurance Law, Law Press,2016

[4] Sun Qixiang, Comment on the Hot Issues of China's Insurance Market, Peking University Press, (04)2016.

[5] Li Ziyao, The Exploration of the Reform of the Teaching Methods of the Course of Insurance, Journal of Hubei Institute of science and technology, Phase 08 of 2015 